\title{
GMR
}

\section{Effect of everolimus on the expression of Ki-67 and caspase- 3 in patients with neuroendocrine tumors}

\author{
H.Y. Zhang ${ }^{1,2}$, X.B. Cheng ${ }^{1}$, Y. Li ${ }^{2}$, L.D. Jin ${ }^{3}$ and H.P. Yin ${ }^{2}$ \\ ${ }^{1}$ Department of Endocrinology, The First Affiliated Hospital of Soochow University, \\ Suzhou, Jiangsu Province, China \\ ${ }^{2}$ Department of Geriatrics, First People's Hospital of Yunnan Province, \\ Kunming, Yunnan Province, China \\ ${ }^{3}$ Department of Neurosurgery, First People's Hospital of Yunnan Province, \\ Kunming, Yunnan Province, China \\ Corresponding author: X.B. Cheng \\ E-mail: xingbocheng332@sina.com \\ Genet. Mol. Res. 16 (1): gmr16019486 \\ Received October 27, 2016 \\ Accepted February 23, 2017 \\ Published March 30, 2017 \\ DOI http://dx.doi.org/10.4238/gmr16019486 \\ Copyright $(2017$ The Authors. This is an open-access article distributed under the terms of \\ the Creative Commons Attribution ShareAlike (CC BY-SA) 4.0 License.
}

\begin{abstract}
Tumors, especially neuroendocrine tumors (NETs), can cause adverse effects on human health. The expression and significance of Ki-67 and caspase-3 in NET remain to be further explored. Everolimus is an important drug used for the treatment of NETs. In this study, we aimed to investigate whether everolimus exerts anti-tumor effects by suppressing the expression of Ki-67 and caspase-3 in NET. Tumor (different developmental stages) and adjacent tissues were collected from patients with NET. The expression of Ki-67 and caspase- 3 were detected in 244 paraffin sections of NET using immunohistochemistry. RT-PCR and western blot were used to detect the expression of Ki-67 and caspase-3 at mRNA and protein levels, respectively. The patients $(\mathrm{N}=244)$ were randomly divided into everolimus-intervention and control groups. RT-PCR and western blot were used to measure the
\end{abstract}

Genetics and Molecular Research 16 (1): gmr16019486 
expression changes of Ki-67 and caspase- 3 before and after everolimus treatment. The rates of Ki-67 expression in NET grades 1-6 were 14.2, $22.1,37.5,59.9,69.9$, and $77.8 \%$, respectively. The difference between the groups was significant. The rates of caspase- 3 expression in NET grades $1-6$ were $28.6,33.3,31.3,60.0,80.0$, and $88.9 \%$, respectively, and the difference between groups was significant. Moreover, the expression of Ki-67 and caspase-3 showed a significant negative correlation. The expression of Ki-67 decreased while that of caspase-3 increased after everolimus treatment. In conclusion, the decrease in $\mathrm{Ki}-$ 67 expression and increase in caspase- 3 expression after everolimus treatment indicated that everolimus exerted its anti-cancer effect by regulating the expression of Ki-67 and caspase-3.

Key words: Everolimus; Neuroendocrine tumors; Ki-67; Caspase-3; Immunohistochemistry

\section{INTRODUCTION}

Neuroendocrine tumor (NET), a rare tumor arising from the cells of nervous system, accounts for about $3-5 \%$ of all nervous system tumors. NET can be divided into different developmental phases according to the type, amount of hormone secreted, and clinical pathology of patients (Phan, 2015). At different stages of development, NET tissues or cells express specific proteins, for example, molecules involved in multiple physiological processes such as caspase-3 and Ki-67, cyclins, and signaling molecules such as mechanistic target of rapamycin (mTOR). These molecules are often used for the diagnosis, treatment, and prognosis of NET (Grandhi et al., 2015; Cloyd and Poultsides, 2015). However, the expression of caspase-3 and Ki-67 at different stages of NET development has yet to be explored (Strosberg et al., 2015a).

The commonly used treatments for NET are radical surgery and cytoreductive surgery (Schneider et al., 2015). Although surgery plays an important role in the treatment of NET, metastases were found in most patients with NET, indicating that these patients lost the best timing of surgical treatment (Jiménez-Fonseca et al., 2015; Sugimoto et al., 2015). For NET

patients with metastases, chemotherapy is one of the most important treatment approaches for controlling tumor development and clinical symptoms (Claringbold and Turner, 2015). The most commonly used chemotherapy drugs are everolimus, cisplatin, nimustine, and carmustine (Capozzi et al., 2015; Nahmias et al., 2015).

Everolimus, an important drug in the treatment of cancer, inhibits mechanistic target of rapamycin (mTOR), which is a serine/threonine kinase widely present in various types of cells with highly conserved protein structures (Ortolani et al., 2015; Filosso et al., 2015). Everolimus is used as an mTOR inhibitor for basic research. Clinically, everolimus is approved by FDA for the prevention of immunological rejection in heart and kidney transplant patients. In addition, it has been used to treat pancreatic NET and renal carcinoma in recent years (Panzuto et al., 2015; Dasari et al., 2015). Its outstanding features are effective targeting property, specific killing of tumor cells with minimal side effects, and fewer clinical complications (Bilici, 2015). Studies have found that everolimus might have many antitumor activities, such as vascular protective, antiviral, and immune-boosting effects (Weber, 2014; Anthony et al., 2015). However, the molecular mechanism underlying the anti-cancer effect of everolimus in NET remains to be elucidated.

Genetics and Molecular Research 16 (1): gmr16019486 
Nuclear-associated antigen Ki-67 is an important cell proliferation-associated nuclear antigen (Strosberg et al., 2015b). It is believed that the occurrence of cancer is closely related to cellular hyperproliferation. Hyperproliferation of malignant tumor cells leads to tumor over-growth and progression (Pusceddu et al., 2014). As executors of apoptosis, caspase-3 mediates both mitochondrial and death receptor pathways of apoptosis (Abdel-Rahman and Fouad, 2015). The reduction of tumor cell apoptosis is another important feature of caspase- 3 (Hobday et al., 2015). However, the expression profiles of Ki-67 and caspase-3 at different developmental stages of NETs remain poorly understood.

In this study, the expression levels of Ki-67 and caspase-3 were measured using immunohistochemistry, RT-PCR, and western blotting. In addition, the anti-tumor effect of everolimus through the regulation of Ki-67 and caspase-3 expression was investigated.

\section{MATERIAL AND METHODS}

\section{Materials}

Mouse anti-Human Ki-67 and mouse anti-Human caspase-3 monoclonal antibodies were purchased from Sigma (St. Louis, MO, USA). Immunohistochemistry StreptavidinPeroxidase (S-P) kit was purchased from DingGuo Biotechnology. Co., Ltd. (Beijing, China). DAB (3,3-diaminobenzidine) chromogenic enzyme substrate kit was purchased from TianGen Biotech Co. Ltd. (Beijing, China). Real-time polymerase chain reaction (RT-PCR) kit was purchased from Beyotime Biotechnology Co. Ltd. (Nantong, Jiangsu, China). All other reagents were purchased from DingGuo Biotechnology (Beijing, China).

\section{Sampling of NET subjects}

Two hundred forty-four patients with NET admitted in our hospital from August 2011 to August 2015 were included in this study. These patients $(\mathrm{N}=244)$ were randomly divided into control (no everolimus treatment) and everolimus groups prior to surgery. All patients received a diagnosis of NET by clinical pathology. Inclusion and exclusion criteria similar to previous studies were followed (Lombard-Bohas et al., 2015; Yao et al., 2015). All patients have intact clinical data.

The subjects included 112 men and 132 women aged $20-80$ years, with a mean age of 47.5. According to the NET 5-grade criteria published by the World Health Organization in 2014 (Mitsuyama et al., 2015), 28 patients were grade one, 36 grade two, 64 grade three, 40 grade four, 40 grade 5, and 36 grade 6 . Grade 1-3 was defined as low level of NETs and grand 4-6 was defined as high level of NETs. This study was approved by the Medical Ethics Committee of the First Affiliated Hospital of Soochow University. Informed consents were obtained from all participants prior to the study.

\section{Immunohistochemistry}

Streptavidin-peroxidase (SP) method was used for immunohistochemical staining and analysis (Valle et al., 2014). Briefly, NET and control tissues were embedded in paraffin, conventionally sliced, dewaxed with xylene, and hydrated with different concentrations of ethanol. Endogenous peroxidase was blocked in $5 \% \mathrm{H}_{2} \mathrm{O}_{2}$ at room temperature for 8 min,

Genetics and Molecular Research 16 (1): gmr16019486 
followed by washing with PBS three times. The slices were then incubated with mouse antiHuman Ki-67 and mouse anti-Human caspase-3 primary antibodies (1: 1000 dilution) at $25^{\circ} \mathrm{C}$ for $2 \mathrm{~h}$, followed by washing with PBS three times. Subsequently, the slices were incubated with goat anti-mouse secondary antibodies at room temperature for $1 \mathrm{~h}$, washed with PBS three times, followed by incubation with DAB reagent for $8 \mathrm{~min}$ at room temperature. After termination of the reaction, the slices were stained with hematoxylin, followed by conventional dehydration and transparency, and neutral resin mounting. For negative control, PBS was used instead of primary antibody. Breast cancer tissue sections were used as positive controls.

\section{Interpretation of immunohistochemistry results}

Immunohistochemistry results were read by three independent pathologists in a double-blind fashion (Yoshizawa et al., 2014). The staining intensity was scored as follows: colorless, 0 ; yellow, 1; brown, 2; and tan, 3 . The percentage of positive cells was scored as follows: negative, $0 ; \leq 10 \%$ positive cells, $1 ; 11$ to $50 \%$ positive cells, $2 ; 51$ to $75 \%$ positive cells, $3 ;>75 \%$ positive cells, 4 . If the product of the percentage of positive cells and staining intensity was greater than 3 , then the case was defined as immunoreactive positive. Each sample had three repeats. Three homogeneously staining regions were randomly selected from each slice to observe and calculate the percentage of positive staining cells. Ki-67 positive staining showed purple or brownish purple granules in the nucleus. Caspase-3 positive staining showed red or purple granules in the nucleus or cytoplasm.

\section{RT-PCR}

Total RNA from NET and control tissues was extracted and RT-PCR was performed according to the kit instructions (Panzuto et al., 2014). The primer sequences for Ki-67, actin, and caspase-3 were: 5'TAAATGTCATGTAAGTAACAGACAGAACA3'/5'TGTCAACAGA TAAGTAAATGATCAGAACA3'; 5'GACCAACACCTTACAGTTCTAATGCCCCA3'/5'CT ACAGTGACTTCCAACACTAATGCCCCA3'; 5'TTACAGTGAACACCTCTACCAATGC CCCA3'/5'TCCGTGAAAACACTAATCACCTTGCCCCA3'.

The PCR reaction system was as follows: $1 \mu \mathrm{L}$ cDNA solution, $2 \mu \mathrm{L}$ 10X PCR Buffer, $2 \mu \mathrm{L}$ dNTP Mixture $(2 \mathrm{mM}), 1 \mu \mathrm{L}$ primer $1(10 \mu \mathrm{M}), 1 \mu \mathrm{L}$ primer $2(10 \mu \mathrm{M}), 1 \mu \mathrm{L}$ Taq DNA Polymerase, $1 \mu \mathrm{L} \mathrm{MgCl}_{2}(25 \mathrm{mM})$, and $14 \mu \mathrm{L} \mathrm{H}_{2} \mathrm{O}$. PCR was performed as follows: $95^{\circ} \mathrm{C}$ for $5 \mathrm{~min}$, followed by 30 cycles of $95^{\circ} \mathrm{C}$ for $60 \mathrm{~s}, 56^{\circ} \mathrm{C}$ for $30 \mathrm{~s}$, an extension of $72^{\circ} \mathrm{C}$ for $60 \mathrm{~s}$ and final extension of $72^{\circ} \mathrm{C}$ for $10 \mathrm{~min}$.

BandScan 560 software was used to quantify the electrophoretic bands. All genes were independently measured three times, and the average value was used as the final value. The band density ratios of target genes Ki-67 or caspase- 3 to the internal control gene $\beta$-actin were defined as the relative expression of Ki-67 and caspase-3.

\section{Western blot analysis}

Proteins were extracted from NET and control tissues, and their levels were measured by western blot analysis (Ohki et al., 2014). The protein samples were used for Sodium dodecyl sulfate-polyacrylamide gel electrophoresis (SDS-PAGE) and western blotting. The membranes were incubated with anti-Ki-67 antibody (1:1000 dilution), anti-caspase-3 antibody (1:1000

Genetics and Molecular Research 16 (1): gmr16019486 
dilution), and anti-actin antibody (1:1000 dilution) for $2 \mathrm{~h}$ at $25^{\circ} \mathrm{C}$. The membranes were then washed and incubated with anti-mouse secondary antibody for $1 \mathrm{~h}$ at room temperature, followed by developing and fixing.

BandScan 560 software was used to quantify the protein bands. All proteins were independently measured three times, and the average value was used as the final value. The band density ratios of target proteins Ki-67 or caspase- 3 to the loading control protein $\beta$-actin were defined as the relative expression of $\mathrm{Ki}-67$ and caspase-3.

\section{Statistical analysis}

SPSS 13.0 software was used for data analysis and statistics. The data are reported as means \pm standard deviation (SD). Chi-square test and Spearman rank-order correlation were used for correlation analysis. $\mathrm{P}<0.05$ was considered statistically significant.

\section{RESULTS}

\section{Ki-67 expression levels in NETs}

The result of immunohistochemistry of Ki-67 in NET and control tissues is shown in Figure 1. Positive staining of Ki-67 showed purple or brown-purple granules. Results indicated that Ki-67 was highly expressed in the nuclei of the epithelial cells of NET tissue.

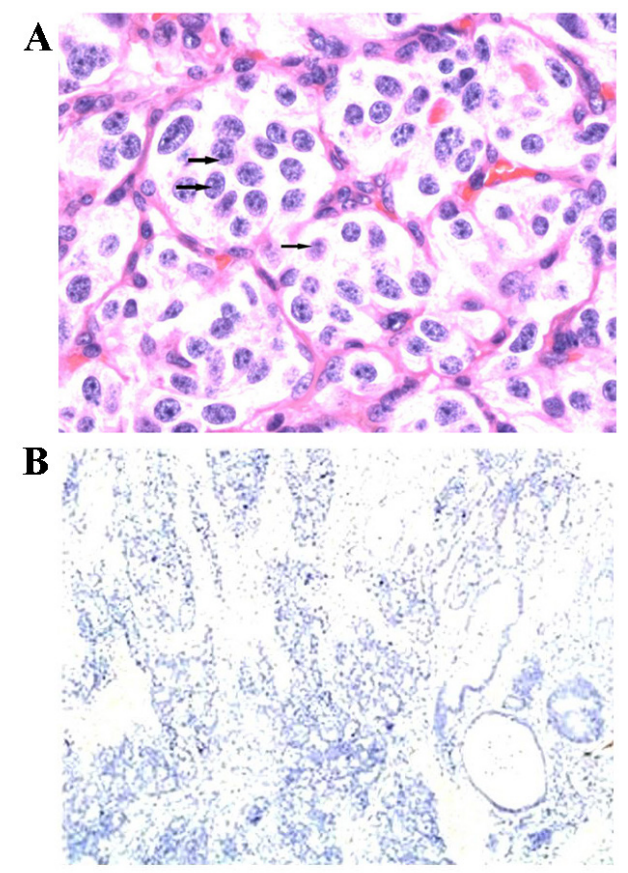

Figure 1. Immunohistochemistry staining of Ki-67 in NET tissues (A) and para-carcinoma tissue (B). Positive staining of Ki-67 showed purple or brown-purple granules. This case was grade four. Arrows indicate positive staining of nuclei.

Genetics and Molecular Research 16 (1): gmr16019486 
Ki-67 expression levels in all NET grades are shown in Table 1. The rates of Ki-67 expression in NET grades $1-6$ were $14.2,22.2,37.5,60.0,70.0$, and $77.8 \%$, respectively. The difference between the groups was significant $\left(\chi^{2}=10.6, \mathrm{P}<0.05\right.$, Table 2$)$.

Table 1. Ki-67 expression in all grades of NETs.

\begin{tabular}{|c|c|c|c|c|c|c|}
\hline \multirow[t]{2}{*}{ NET grades } & \multirow[t]{2}{*}{ Cases $(\mathrm{N})$} & \multicolumn{3}{|c|}{ Ki-67 } & \multirow[t]{2}{*}{$\chi^{2}$} & \multirow[t]{2}{*}{$\mathrm{P}$} \\
\hline & & Negative (N) & Positive (N) & Ratio (\%) & & \\
\hline 1 & 28 & 24 & 4 & 14.2 & \multirow[t]{6}{*}{11.1} & \multirow[t]{6}{*}{0.026} \\
\hline 2 & 36 & 28 & 8 & 22.2 & & \\
\hline 3 & 64 & 40 & 24 & 37.5 & & \\
\hline 4 & 40 & 16 & 24 & 60.0 & & \\
\hline 5 & 40 & 12 & 28 & 70.0 & & \\
\hline 6 & 36 & 8 & 28 & 77.8 & & \\
\hline
\end{tabular}

Table 2. Ki-67 expression in low-level (grades 1-3) and high-level (grades 4-6) NETs.

\begin{tabular}{l|c|c|c|c|c}
\hline \multirow{2}{*}{ NET grades } & Cases $(\mathrm{N})$ & \multicolumn{2}{|c|}{ Ki-67 } & $\chi^{2}$ & P \\
\cline { 3 - 4 } & & Negative $(\mathrm{N})$ & Positive $(\mathrm{N})$ & & \\
\hline Low-level $(1,2,3)$ & 128 & 92 & 36 & 10.6 & 0.002 \\
\hline High-level $(4,5,6)$ & 116 & 36 & 80 & & \\
\hline
\end{tabular}

\section{Caspase-3 expression levels in NETs}

The result of immunohistochemistry of caspase-3 is shown in Figure 2. Positive staining of caspase- 3 showed red or purple granules. The results indicated that caspase- 3 was primarily expressed in the cytosol.

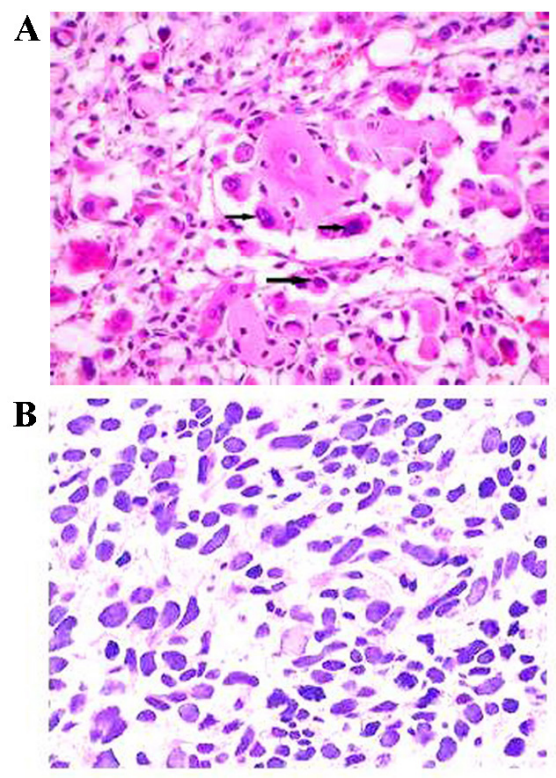

Figure 2. Immunohistochemistry staining of caspase-3 in NET tissues (A) and para-carcinoma tissue (B). Positive staining of caspase- 3 showed red or purple granules. This case was grade four. Arrows indicate positive staining of nuclei.

Genetics and Molecular Research 16 (1): gmr16019486 
The expression levels of caspase- 3 in all grades of NETs are shown in Table 3 . The rates of caspase-3 expression in NET grades 1-6 were 28.6, 33.3, 31.3, 60.0, 80.0, and 88.9\%, respectively. The difference between the groups was significant $\left(\chi^{2}=11.2, \mathrm{P}<0.05\right.$, Tables 3 and 4$)$.

Table 3. Caspase-3 expression in all grades of NETs.

\begin{tabular}{|c|c|c|c|c|c|c|}
\hline \multirow[t]{2}{*}{ NET grades } & \multirow[t]{2}{*}{ Cases $(\mathrm{N})$} & \multicolumn{2}{|c|}{ Caspase-3 } & \multirow[b]{2}{*}{ Ratio (\%) } & \multirow[t]{2}{*}{$\chi^{2}$} & \multirow[t]{2}{*}{$P$} \\
\hline & & Negative (N) & Positive $(\mathrm{N})$ & & & \\
\hline 1 & 28 & 20 & 8 & 28.6 & \multirow[t]{6}{*}{12.9} & \multirow[t]{6}{*}{0.007} \\
\hline 2 & 36 & 24 & 12 & 33.3 & & \\
\hline 3 & 64 & 44 & 20 & 31.3 & & \\
\hline 4 & 40 & 16 & 24 & 60.0 & & \\
\hline 5 & 40 & 8 & 32 & 80.0 & & \\
\hline 6 & 36 & 4 & 32 & 88.9 & & \\
\hline
\end{tabular}

Table 4. Caspase-3 expression in low-level (grades 1-3) and high-level (grades 4-6) NETs.

\begin{tabular}{|c|c|c|c|c|c|}
\hline \multirow[t]{2}{*}{ NET grades } & \multirow[t]{2}{*}{ Cases $(\mathrm{N})$} & \multicolumn{2}{|c|}{ Ki-67 } & \multirow[t]{2}{*}{$\chi^{2}$} & \multirow[t]{2}{*}{$\mathrm{P}$} \\
\hline & & Negative (N) & Positive (N) & & \\
\hline Low-level $(1,2,3)$ & 128 & 88 & 40 & \multirow[t]{2}{*}{11.2} & \multirow[t]{2}{*}{0.0016} \\
\hline High-level $(4,5,6)$ & 116 & 28 & 88 & & \\
\hline
\end{tabular}

\section{Correlation of Ki-67 and caspase-3 in NETs}

Ki-67 and caspase-3 represent the extent of cell proliferation and apoptosis, respectively. The correlation of Ki-67 and caspase-3 expression in NET was analyzed. No significant correlation was found in low-level NETs (Table 5). However, in high-level NETs, the correlation coefficient of Ki-67 and caspase-3 was significant (Table 6).

Table 5. Correlation of Ki-67 and caspase-3 in low-level NETs.

\begin{tabular}{l|c|c|c|c|c}
\hline \multirow{2}{*}{ Ki-67 } & Cases (N) & \multicolumn{2}{|c|}{ Caspase-3 } & R & \multirow{2}{*}{ P } \\
\cline { 3 - 4 } & & Negative (N) & Positive (N) & & \\
\hline Negative & 92 & 60 & 32 & -0.113 & 0.0016 \\
\hline Positive & 36 & 28 & 8 & & \\
\hline
\end{tabular}

Table 6. Correlation of Ki-67 and caspase-3 in high-level NETs.

\begin{tabular}{l|c|c|c|c|c}
\hline \multirow{2}{*}{ Ki-67 } & Cases (N) & \multicolumn{2}{|c|}{ Caspase-3 } & R & \multirow{2}{*}{ P } \\
\cline { 2 - 4 } & & Negative (N) & Positive (N) & & \\
\hline Negative & 36 & 20 & 16 & 0.484 & \\
\hline Positive & 80 & 8 & 72 & & \\
\hline
\end{tabular}

\section{Expression of Ki-67 and caspase-3 in NETs}

RT-PCR and western blotting were used to measure the expression of Ki-67 and caspase-3 in NET and para-carcinoma tissue. The expression level of Ki-67 in NET was much higher than that of para-carcinoma tissue (Figure 3). In contrast, the expression of caspase-3 in NETs was at much lower levels than that of para-carcinoma tissue (Figure 4).

Genetics and Molecular Research 16 (1): gmr16019486 
A

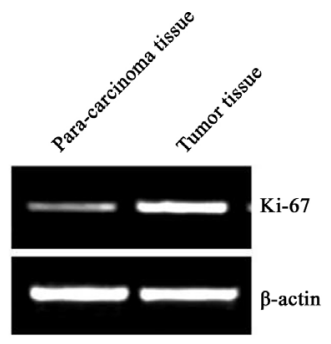

B

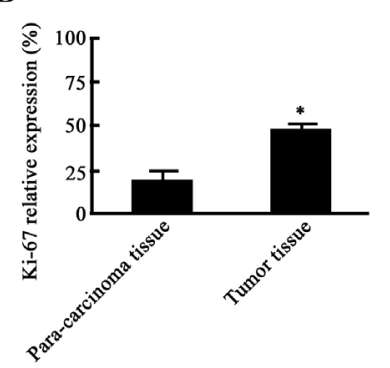

C

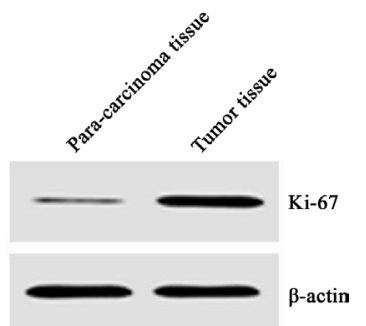

$\mathrm{D} \frac{\mathrm{9}}{\mathrm{e}}$

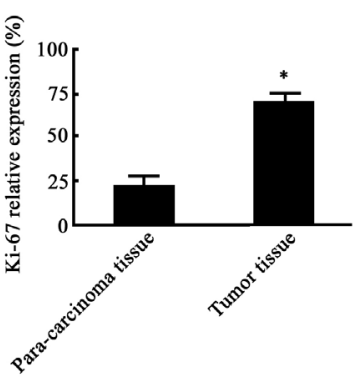

Figure 3. Ki-67 expression in NETs and para-carcinoma tissue. A. RT-PCR of Ki-67; B. quantification of band density; C. western blot analysis of Ki-67; D. quantification of band density.

A

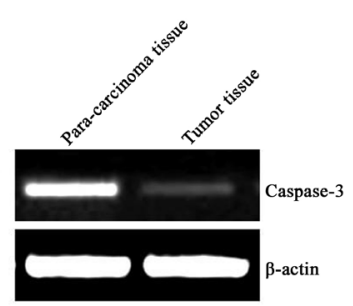

B

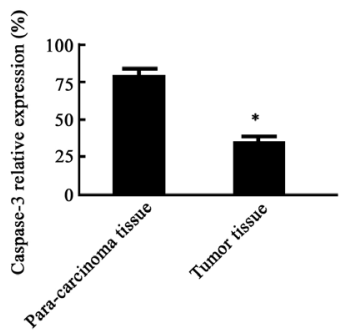

C

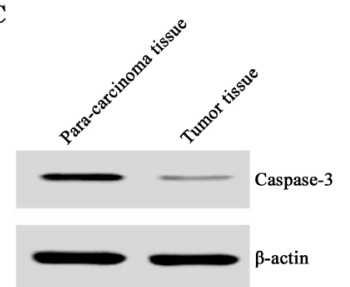

$\mathrm{D} \cong$

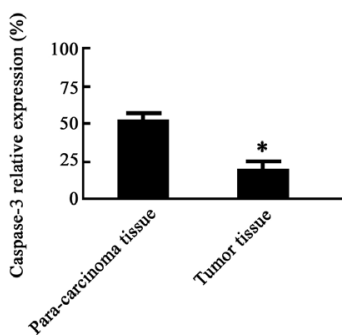

Figure 4. Caspase-3 expression in NETs and para-carcinoma tissue. A. RT-PCR of caspase-3; B. quantification of band density; C. western blot analysis of caspase-3; D. quantification of band density.

\section{Expression of Ki-67 and caspase-3 in NETs after everolimus treatment}

Everolimus treatment in patients with NET decreased the expression level of Ki-67 in the NET tissue (Figure 5), but increased the expression of caspase-3 (Figure 6). These data suggest that everolimus may exert its anti-tumor effect through the regulation of Ki-67 and caspase-3 expression.

Genetics and Molecular Research 16 (1): gmr16019486 
A
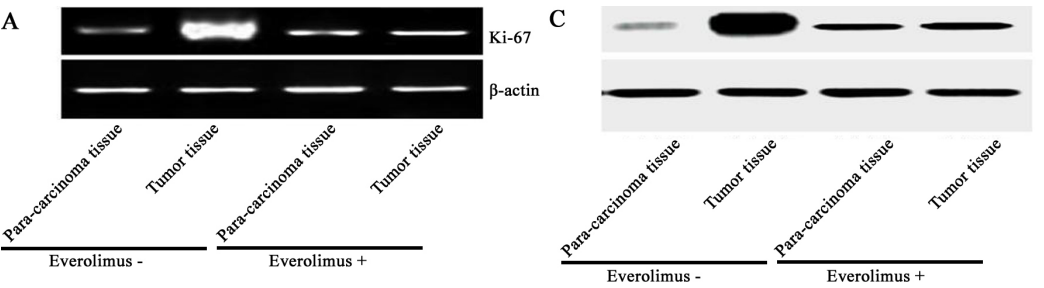

B
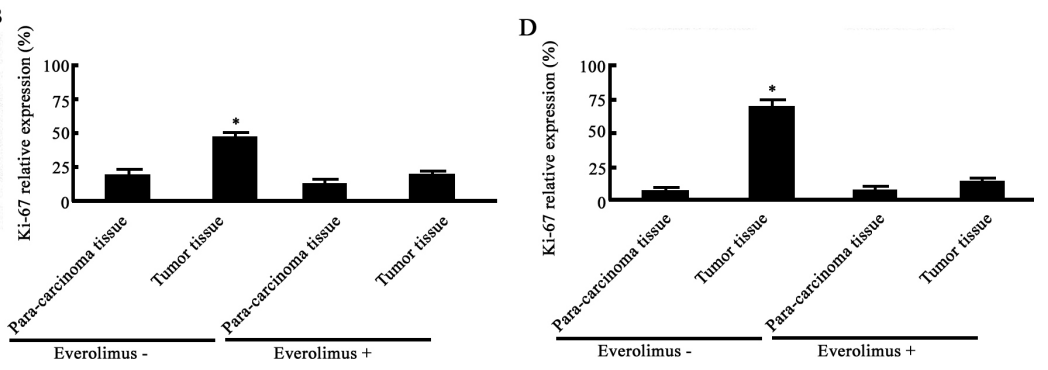

Figure 5. Expression of Ki-67 in NETs after treatment with everolimus. A. RT-PCR of caspase-3; B. quantification of band density; C. western blot analysis of caspase-3; D. quantification of band density.
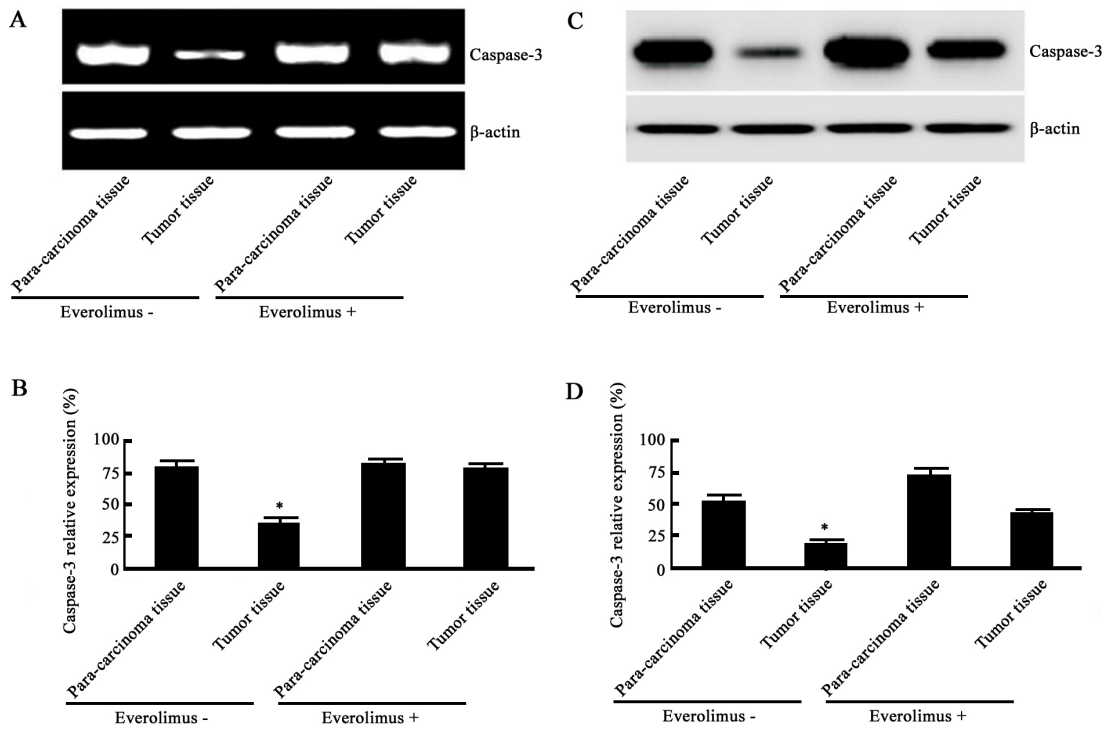

Figure 6. Expression of caspase-3 in NETs after treatment with everolimus. A. RT-PCR of caspase- 3 ; B. quantification of band density; C. western blot analysis of caspase-3; D. quantification of band density.

\section{DISCUSSION}

The increase in incidence and mortality of NET owing to the improvement of living standards and change of lifestyle has become a serious threat to people's health (Phan, 2015). However, the molecular mechanism underlying the pathogenesis of NET remains to be further 
explored. Studies showed that the expression of Ki-67 and caspase-3 was closely correlated with the occurrence and development of breast (Deniz et al., 2015) and pancreatic cancers (Hu et al., 2012). However, the expression profiles and roles of Ki-67 and caspase-3 in NET remains poorly understood.

In this study, we first examined the expression levels of Ki-67 and caspase-3 in NET and their relationship with NET grades. Secondly, we examined whether everolimus exerted its anti-tumor effect through the regulation of Ki-67 and caspase- 3 expression in NETs. The key observations of the results of this study are as follows: first, along with the development of NET, the expression levels of Ki-67 increased, whereas those of caspase-3 decreased. Second, the expression levels of Ki-67 and caspase- 3 were correlated with the grading of NET. This finding was consistent with that of previous studies showing that the expression levels of Ki-67 and caspase-3 were correlated with the occurrence and development of cancer (Deniz et al., 2015; Hu et al., 2012). Third, the expression levels of Ki-67 decreased and those of caspase-3 increased after everolimus treatment. The results of the present study further confirmed this concept.

Everolimus is an important drug for the treatment of NET (Anthony et al., 2015). The results of this study showed that everolimus treatment decreased the expression of Ki-67, whereas the expression of caspase- 3 was increased, indicating that everolimus may exert its anti-tumor effects by inducing apoptosis of tumor cells. These findings were consistent with those of a previous study showing that everolimus induces apoptosis in human nasopharyngeal carcinoma cells (Cai et al., 2013).

It is worth to mention that only 244 cases were included in this study. Therefore, it would be more informative to expand the sample size to further confirm the conclusions. The relationship between prognosis of NET with the expression levels of Ki-67 and caspase-3 have not been studied. Therefore, establishing NET animal models or inducing overexpression/knockdown of Ki-67 and caspase-3 could help to explore the association between Ki-67 and caspase-3 and tumor cell proliferation and apoptosis in vivo. The exact mechanism by which Ki-67 and caspase-3 are involved in the pathogenesis of NET was not studied in the present study. This is the main limitation of our study and requires further investigation.

In short, our study showed that along with the development of NETs, the expression of Ki-67 increased, while that of caspase-3 decreased. However, everolimus treatment decreased the expression of Ki-67 and increased the expression of caspase-3, suggesting that everolimus exerts its anti-tumor effect by regulating the expression levels of Ki-67 and caspase-3. In addition, our results suggested that Ki-67 and caspase- 3 have a significant antagonistic interaction in the occurrence and development of NET, indicating that the combined examination of both Ki-67 and caspase-3 in NETs may have a significant effect on NET prognosis as reliable biomarkers.

\section{Conflicts of interest}

The authors declare no conflict of interest.

\section{ACKNOWLEDGMENTS}

We would like to thank the anonymous reviewers for reviewing this manuscript.

Genetics and Molecular Research 16 (1): gmr16019486 


\section{REFERENCES}

Abdel-Rahman O and Fouad M(2015). Everolimus-based combination for the treatment of advanced gastroenteropancreatic neuroendocrine neoplasms (GEP-NENs): biological rationale and critical review of published data. Tumour Biol. 36: 467-478. http://dx.doi.org/10.1007/s13277-015-3064-4

Anthony LB, Pavel ME, Hainsworth JD, Kvols LK, et al. (2015). Impact of Previous Somatostatin Analogue Use on the Activity of Everolimus in Patients with Advanced Neuroendocrine Tumors: Analysis from the Phase III RADIANT-2 Trial. Neuroendocrinology 102: 18-25. http://dx.doi.org/10.1159/000381715

Bilici A (2015). Advances in the management of unresectable or metastatic pancreatic neuroendocrine tumors: chemotherapy, targeted therapy, hormonal treatment, and future directions. Asian Pac. J. Cancer Prev. 16: 21512159. http://dx.doi.org/10.7314/APJCP.2015.16.6.2151

Cai Y, Xia Q, Su Q, Luo R, et al. (2013). mTOR inhibitor RAD001 (everolimus) induces apoptotic, not autophagic cell death, in human nasopharyngeal carcinoma cells. Int. J. Mol. Med. 31: 904-912.

Capozzi M, Caterina I, De Divitiis C, von Arx C, et al.; ENETS Center of Excellence Multidisciplinary Group for Neuroendocrine Tumors in Naples (Italy) (2015). Everolimus and pancreatic neuroendocrine tumors (PNETs): Activity, resistance and how to overcome it. Int. J. Surg. 21 (Suppl 1): S89-S94. http://dx.doi.org/10.1016/j. ijsu.2015.06.064

Claringbold PG and Turner JH (2015). NeuroEndocrine Tumor Therapy with Lutetium-177-octreotate and Everolimus (NETTLE): A Phase I Study. Cancer Biother. Radiopharm. 30: 261-269. http://dx.doi.org/10.1089/cbr.2015.1876

Cloyd JM and Poultsides GA (2015). Non-functional neuroendocrine tumors of the pancreas: Advances in diagnosis and management. World J. Gastroenterol. 21: 9512-9525. http://dx.doi.org/10.3748/wjg.v21.i32.9512

Dasari A, Phan A, Gupta S, Rashid A, et al. (2015). Phase I study of the anti-IGF1R antibody cixutumumab with everolimus and octreotide in advanced well-differentiated neuroendocrine tumors. Endocr. Relat. Cancer 22: 431-441. http:// dx.doi.org/10.1530/ERC-15-0002

Deniz F, Dilek K, Hande M, Umit UM, et al. (2015). Ki-67 and caspase expression in breast carcinoma: does variance in locational sampling exist? Int. J. Clin. Exp. Pathol. 8: 11305-11313.

Filosso PL, Ferolla P, Guerrera F, Ruffini E, et al.; European Society of Thoracic Surgeons Lung Neuroendocrine Tumors Working-Group Steering Committee (2015). Multidisciplinary management of advanced lung neuroendocrine tumors. J. Thorac. Dis. 7 (Suppl 2): S163-S171.

Grandhi MS, Lafaro KJ and Pawlik TM (2015). Role of Locoregional and Systemic Approaches for the Treatment of Patients with Metastatic Neuroendocrine Tumors. J. Gastrointest. Surg. 19: 2273-2282. http://dx.doi.org/10.1007/ s11605-015-2931-z

Hobday TJ, Qin R, Reidy-Lagunes D, Moore MJ, et al. (2015). Multicenter Phase II Trial of Temsirolimus and Bevacizumab in Pancreatic Neuroendocrine Tumors. J. Clin. Oncol. 33: 1551-1556. http://dx.doi.org/10.1200/JCO.2014.56.2082

Hu HY, Liu H, Zhang JW, Hu K, et al. (2012). Clinical significance of Smac and Ki-67 expression in pancreatic cancer. Hepatogastroenterology 59: 2640-2643.

Jiménez-Fonseca P, Carmona-Bayonas A, Martín-PérezE, Crespo G, et al.; Spanish Neuroendocrine Tumor Group (GETNE) (2015). Health-related quality of life in well-differentiated metastatic gastroenteropancreatic neuroendocrine tumors. Cancer Metastasis Rev. 34: 381-400. http://dx.doi.org/10.1007/s10555-015-9573-1

Lombard-Bohas C, Yao JC, Hobday T, Van Cutsem E, et al. (2015). Impact of prior chemotherapy use on the efficacy of everolimus in patients with advanced pancreatic neuroendocrine tumors: a subgroup analysis of the phase III RADIANT-3 trial. Pancreas 44: 181-189. http://dx.doi.org/10.1097/MPA.0000000000000262

Mitsuyama T, Kubota M, Nakamura Y, Yuzurihara M, et al. (2015). Neuroendocrine tumor arising from tailgut cyst with spinal cord tethering: case report and literature review. Spine J. 15: e1-e8. http://dx.doi.org/10.1016/j. $\underline{\text { spinee.2014.09.027 }}$

Nahmias A, Grozinsky-Glasberg S, Salmon A and Gross DJ (2015). Pancreatic neuroendocrine tumors with transformation to insulinoma: an unusual presentation of a rare disease. Endocrinol. Diabetes Metab. Case Rep. 2015: 150032.

Ohki R, Saito K, Chen Y, Kawase T, et al. (2014). PHLDA3 is a novel tumor suppressor of pancreatic neuroendocrine tumors. Proc. Natl. Acad. Sci. USA 111: E2404-E2413. http://dx.doi.org/10.1073/pnas.1319962111

Ortolani S, Ciccarese C, Cingarlini S, Tortora G, et al. (2015). Suppression of mTOR pathway in solid tumors: lessons learned from clinical experience in renal cell carcinoma and neuroendocrine tumors and new perspectives. Future Oncol. 11: 1809-1828. http://dx.doi.org/10.2217/fon.15.81

Panzuto F, Rinzivillo M, Fazio N, de Braud F, et al. (2014). Real-world study of everolimus in advanced progressive neuroendocrine tumors. Oncologist 19: 966-974. http://dx.doi.org/10.1634/theoncologist.2014-0037

Panzuto F, Rinzivillo M, Fazio N, de Braud F, et al. (2015). Real-world study of everolimus in advanced progressive

Genetics and Molecular Research 16 (1): gmr16019486 
neuroendocrine tumors. Oncologist 20:570. http://dx.doi.org/10.1634/theoncologist.2014-0037erratum

Phan AT (2015). Randomized phase II study of everolimus (E) versus everolimus plus bevacizumab (E+B) in patients (Pts) with locally advanced or metastatic pancreatic neuroendocrine tumors. Clin. Adv. Hematol. Oncol. 13: 8-10.

Pusceddu S, de Braud F, Concas L, Bregant C, et al. (2014). Rationale and protocol of the MetNET-1 trial, a prospective, single center, phase II study to evaluate the activity and safety of everolimus in combination with octreotide LAR and metformin in patients with advanced pancreatic neuroendocrine tumors. Tumori 100: e286-e289.

Schneider TC, de Wit D, Links TP, van Erp NP, et al. (2015). Beneficial Effects of the mTOR Inhibitor Everolimus in Patients with Advanced Medullary Thyroid Carcinoma: Subgroup Results of a Phase II Trial. Int. J. Endocrinol. 2015: 348124. http://dx.doi.org/10.1155/2015/348124

Strosberg J, Goldman J, Costa F and Pavel M (2015a). The Role of Chemotherapy in Well-Differentiated Gastroenteropancreatic Neuroendocrine Tumors. Front. Horm. Res. 44:239-247. http://dx.doi.org/10.1159/000403785

Strosberg JR, Fisher GA, Benson AB, Anthony LB, et al. (2015b). Appropriateness of systemic treatments in unresectable metastatic well-differentiated pancreatic neuroendocrine tumors. World J. Gastroenterol. 21: 2450-2459. http:// dx.doi.org/10.3748/wjg.v21.i8.2450

Sugimoto M, Takagi T, Hikichi T, Suzuki R, et al. (2015). Efficacy of endoscopic ultrasonography-guided fine needle aspiration for pancreatic neuroendocrine tumor grading. World J. Gastroenterol. 21: 8118-8124.

Valle JW, Faivre S, Hubner RA, Grande E, et al. (2014). Practical management of sunitinib toxicities in the treatment of pancreatic neuroendocrine tumors. Cancer Treat. Rev. 40: 1230-1238. http://dx.doi.org/10.1016/j.ctrv.2014.09.001

Weber M (2014). New directions in the treatment of gastroenteropancreatic neuroendocrine tumors (GEP-NETs): shifting from symptom management to targeting tumors. Clin. Adv. Hematol. Oncol. 12 (Suppl 19): 12-17.

Yao JC, Phan AT, Hess K, Fogelman D, et al. (2015). Perfusion computed tomography as functional biomarker in randomized run-in study of bevacizumab and everolimus in well-differentiated neuroendocrine tumors. Pancreas 44: 190-197. http://dx.doi.org/10.1097/MPA.0000000000000255

Yoshizawa N, Hijioka S, Mizuno N, Hara K, et al. (2014). A patient with a pancreatic neuroendocrine tumor who developed everolimus-induced interstitial pneumonia: a case report. Nippon Shokakibyo Gakkai Zasshi 111: 1820-1828.

Genetics and Molecular Research 16 (1): gmr16019486 